\title{
A RESSIGNIFICAÇÃO DA ÁREA DE GESTÃO DE PESSOAS E OS NOVOS PAPÉIS DAS PESSOAS E DAS ORGANIZAÇÕES
}

\author{
A. B. C. de CASTRO ${ }^{1}$, L. M. P. BRITO ${ }^{2}$ e J. H. de S. VARELA ${ }^{3}$ \\ ${ }^{1}$ Instituto Federal de Educação, Ciência e Tecnologia do Rio Grande do Norte, ${ }^{2}$ Universidade Potiguar e \\ ${ }^{3}$ Universidade Federal do Rio Grande do Norte \\ brunnicastro@hotmail.com¹ , lydiampbrito@yahoo.com.br² ${ }^{2}$ jhadassa1@hotmail.com ${ }^{3}$
}

Submetido 07/10/2016 - Aceito 13/09/2017

DOI: $10.15628 /$ holos.2017.5168

\section{RESUMO}

O objetivo desse trabalho é conhecer a nova lógica de gestão das pessoas nas organizações em busca do conhecimento e os novos papéis que os trabalhadores assumem nesse contexto. Partiu-se do pressuposto que os novos modelos de gestão exigem novos papéis de trabalhadores e de gestão de pessoas nas organizações. As teorias administrativas analisadas são principalmente de Nonaka e Takeuchi (1997), Brito (2005), Reinhardt et al. (2011), Fukunaga et al. (2015), Freire et al. (2016) e Castro e Brito (2016). Trata-se de um ensaio teórico cujas considerações provisórias sinalizam que o papel dos trabalhadores é saber alocar o conhecimento para uso produtivo, combinar competências no processo criativo para gerar a inovação, desenvolver a escolaridade viabilizando-se o saber fazer através das experiências e da proficiência práticas para construção de novos conhecimentos, desenvolver atitude cooperativa para saber trabalhar em equipes complementares e multidisciplinares, procurar o desenvolvimento e atualização constante das competências requeridas pela organização através de educação e treinamento para o trabalho. Enquanto, o papel das organizações é de apoiar e estimular as atividades criadoras de conhecimento dos indivíduos, ou seja, prover condições facilitadoras para o desenvolvimento dos trabalhadores e ressignificar a gestão de pessoas. Portanto, a educação para o trabalho se configura como a espinha dorsal da gestão do trabalho com pessoas tornando-se uma questão estratégica para as organizações.

PALAVRAS-CHAVE: Novos modelos de gestão; Ressignificação da gestão de pessoas; Papel dos trabalhadores; papel das organizações.

\section{THE RESSIGNIFICATION OF THE AREA OF MANAGEMENT OF PEOPLE AND THE NEW ROLES OF PEOPLE AND ORGANIZATIONS}

\begin{abstract}
The objective of this work is to know the new management logic of the people in the organizations in search of the knowledge and the new roles that the workers assume in that context. It was assumed that the new management models require new roles of workers and people management in organizations. The administrative theories analyzed are mainly from Nonaka and Takeuchi (1997), Brito (2005), Reinhardt et al. (2011), Fukunaga et al. (2015), Freire et al. (2016) and Castro e Brito (2016). This is a theoretical essay whose provisional considerations indicate that the role of workers is to know how to allocate knowledge for productive use, to combine skills in the creative process to generate innovation, to develop education by making
\end{abstract}

know-how feasible through experiences and proficiency practices to build new knowledge, develop cooperative attitude to know how to work in complementary and multidisciplinary teams, seek the development and constant updating of the skills required by the organization through education and training for work. In the meantime, the role of organizations is to support and stimulate activities that create individuals' knowledge, that is, to provide conditions that are conducive to the development of workers and to resignify people management. Therefore, education for work is configured as the backbone of managing work with people becoming a strategic issue for organizations.

KEYWORDS: New management models; Reinterpretation of people management; Role of workers; role of organizations. 


\section{INTRODUÇÃO}

Desde o século $X X$, tendo sido intensificado no século $X X I$, destaca-se um aumento evolutivo das atividades em busca do modelo teórico da Gestão do Conhecimento (GC) que vem gerando cada vez mais avanços tecnológicos e vantagem competitiva para as organizações.

A valorização do conhecimento como bem administrativo-econômico para as pessoas e as organizações pode ser percebida, por exemplo, no relatório Knowledge Economy Program (Brinkley, 2006), divulgado em 2006 que destacou a importância de:

a) explorar o conhecimento por meio das redes e tecnologias de informação e comunicação, para ganhos em vantagem competitiva;

b) compartilhar o conhecimento com os outros em dada economia (por exemplo, com fornecedores, parceiros e clientes). Entretanto, pode haver restrição deste compartilhamento para evitar benefício de concorrentes;

c) Regular a criação de conhecimento (propriedade intelectual) e proibição da difusão indevida do mesmo;

d) Diferenciar conhecimento explícito e tácito;

e) Diferenciar as organizações pela exploração do conhecimento tácito;

f) Mitigar os riscos da gestão do conhecimento por meio de contratos para retenção de trabalhadores chave.

Porém, as várias pesquisas tanto em organizações públicas, quanto em organizações privadas brasileiras disponíveis nos repositórios acadêmicos, ainda apontam que o foco do gerenciamento do conhecimento ainda está na obtenção e disseminação do conhecimento, na fase tática de Gestão do Conhecimento (que tratam sobre a necessidade de aquisição de conhecimento para resolver problemas do dia a dia), conforme Bukowitz e Williams (2002); Geisler e Wickramasinghe (2009); Kim, Lee, Chun e Benbasat (2014); Massingham (2014); Becerra-Fernandez e Sabherwal (2015), o que indica a ausência de uma gestão estratégia sistemática e formal que viabilize o processo de GC considerando-se as demandas de conhecimento emergentes na sociedade, a necessidade de seu gerenciamento e de resultados para as pessoas e para as organizações.

Portanto, entender como a GC pode ser viabilizada nas organizações, inclusive por meio dos trabalhadores, é o ponto de partida para que as organizações saibam planejar, obter, utilizar, aprender, contribuir, avaliar, construir e descartar conhecimentos relacionadas à missão, visão de futuro, negócio, estratégias e valores organizacionais para agirem também de forma estratégica.

Nesse sentido, a questão que emerge neste ensaio teórico, com finalidade exploratóriodescritiva é: qual é o papel das organizações e dos trabalhadores no movimento em busca do gerenciamento do conhecimento? O objetivo é conhecer a nova lógica de gestão das pessoas nas organizações em busca do conhecimento e os novos papéis que os trabalhadores assumem nesse contexto. Partiu-se do pressuposto que os novos modelos de gestão exigem novos papéis de 
trabalhadores e de gestão de pessoas nas organizações. As teorias administrativas analisadas são principalmente de Nonaka e Takeuchi (1997), Brito (2005), Reinhardt, Schmidt, Sloep e Drachsler (2011), Fukunaga, Macedo, Santos, Carvalho e Almeida (2015), Freire et al. (2016) e Castro e Brito (2016).

Este ensaio teórico se justifica pela possibilidade de criação de novos olhares, conteúdos e conceitos sobre o papel das pessoas e das organizações frente aos modelos emergentes de gestão, e porque seus resultados poderão gerar reflexões e possibilidades de práticas organizacionais relacionadas a GC que poderão se reverter em benefícios para as organizações.

\title{
2 PAPEL DAS ORGANIZAÇÕES: RESSIGNIFICAÇÃO DA ÁREA DE GESTÃO DE PESSOAS
}

Gestão de pessoas, conforme França (2007, p.4),

\begin{abstract}
Relaciona-se com os mais variados espaços organizacionais: novas tecnologias; reduções ou novas posições na empresa; contratação incluindo recrutamento e seleção de pessoas; treinamento e desenvolvimento; remuneração e benefícios; banco de talentos; segurança, saúde e qualidade de vida; comunicação com empregados; engenharia de produção e ergonomia; sistemas de gestão da qualidade; inovação tecnológica; desenvolvimento sustentável ou marketing social; competências integrada aos aspectos socioeconômicos e pessoais.
\end{abstract}

Desde os anos 90 os subsistemas de gestão de pessoas adquiriram certo contexto estratégico, pois se passou a vincular suas práticas à estratégia empresarial. Ulrich (1998, p. 233) coloca que, "RH estratégico é assumido, dirigido e utilizado por gerentes de linha para que apliquem as devidas estratégias nesse setor". Nesse sentido, definiu-se gestão estratégica de pessoas como "um conjunto de práticas ou missão, políticas e processos da gestão, característicos das organizações nesta era de competitividade". (Leone, 2007, p. 165).

O quadro a seguir aborda as práticas, missões, as políticas e os processos para melhor compreensão do conceito da autora Leone (2007).

Quadro 1: As práticas, políticas e processos da gestão de pessoas

\begin{tabular}{|c|c|l|}
\hline Práticas ou Missão & \multicolumn{1}{|c|}{ Políticas } & \multicolumn{1}{|c|}{ Processos } \\
\hline Aquisição & O que as pessoas farão na empresa & $\begin{array}{l}\text { Cargos } \\
\text { Recrutamento } \\
\text { Seleção } \\
\text { Socialização }\end{array}$ \\
\hline Estimulação & Como manter as pessoas trabalhando na \\
empresa & $\begin{array}{l}\text { Remuneração } \\
\text { Avaliação de Desempenho } \\
\text { Qualidade de Vida no Trabalho }\end{array}$ \\
\hline Desenvolvimento & Como preparar e desenvolver as pessoas \\
na empresa & $\begin{array}{l}\text { Treinamento e Desenvolvimento } \\
\text { Planejamento de Carreira } \\
\text { Comunicação }\end{array}$ \\
\hline
\end{tabular}

Fonte: Adaptado de Leone (2007, p. 166). 
Segundo Leone (2007), essas práticas de gestão de pessoas traduzem as ações de: encorajar os trabalhadores potenciais a ingressarem na organização, motivar os atuais trabalhadores a permanecerem, estimular os atuais trabalhadores a produzirem ou a se esforçarem desempenhando um papel mais efetivo.

Segundo Freire et al. (2016), no contexto da Sociedade do Conhecimento em que emergem novos modelos de gestão, os gestores por exemplo, são pressionados a se tornarem líderes e desenvolverem seus trabalhadores com autonomia. Portanto, o papel da área de gestão de pessoas vem, aos poucos, sendo descentralizado. Principalmente a partir do Séc. XXI essa área assumiu responsabilidades estratégicas, além das rotinas operacionais dos subsistemas de $\mathrm{RH}$, pois passou a ser responsável pelo desenvolvimento do capital humano de alto desempenho, dando suporte às outras áreas no que se refere ao desenvolvimento do capital intelectual necessário ao alcance das metas estratégicas e a capacitação de seus líderes para motivarem suas equipes, principalmente os experts, inclusive, para valorização do capital social, pois as organizações passaram do modelo burocrático (baseado na especialização do conhecimento) para o modelo de gestão por processos, em rede e virtual aonde as pessoas trabalham por projetos em times de aprendizagem.

Nesse sentido, conforme Brito (2005), os indicadores que integrados montam o quebracabeça que resulta na implantação do modelo de Gestão do Conhecimento/ Gestão de Competências/ Aprendizagem Organizacional são os produtos, serviços e ações projetadas e implantadas nas dimensões das funções clássicas de $\mathrm{RH}$, diga-se nos subsistemas de RH.

A ressignificação do RH se tornou vital, pois passou a ter um papel ativo nas escolhas estratégicas das organizações, especialmente no tocante à preparação dos talentos para as mudanças. (Bagnoli e Vedovato, 2012).

Quadro 2: Ressignificação das funções clássicas de RH

\begin{tabular}{|c|c|}
\hline Funções clássicas de RH (subsistemas) & Ressignificação \\
\hline Planejamento & $\begin{array}{c}\text { Mapeamento interno e externo do conhecimento/ } \\
\text { competências necessárias para a empresa }\end{array}$ \\
\hline Suprimento (recrutamento e seleção) & Captação do conhecimento/ competências \\
\hline Aplicação (cargos, carreira e avaliação de \\
desempenho) & $\begin{array}{c}\text { Aplicação do conhecimento/ competências individuais e } \\
\text { grupais ao negócio da organização }\end{array}$ \\
\hline Desenvolvimento (treinamento e desenvolvimento) & $\begin{array}{c}\text { Disseminação do conhecimento/ competências, crião de } \\
\text { comunidades de aprendizagem, retenção do conhecimento } \\
\text { do trabalhador (propriedade intelectual) }\end{array}$ \\
\hline Manutenção (salários, benefícios, saúde ocupacional) & $\begin{array}{c}\text { Recompensa pelo conhecimento/ competências } \\
\text { agregadoras de valor ao negócio }\end{array}$ \\
\hline Controle & $\begin{array}{c}\text { Monitoração do processo mediante sistemas integrados } \\
\text { veiculadores de informações sobre os empregados }\end{array}$ \\
\hline
\end{tabular}

Fonte: Adaptado de Brito (2005) e Marques (2015).

Portanto, no contexto dos novos modelos de gestão, as funções clássicas de RH passam a ter as seguintes características: 
- Planejamento: as principais mudanças nesse sistema passam pelo processo de integrar a área de RH ao processo de definição da competência essencial ${ }^{1}$ das organizações e do perfil de competência gerencial (Castro e Brito, 2016), que passa inicialmente pela definição da missão, negócio, intenções estratégicas e visão de futuro, e depois se preocupa com a formação de líderes comprometidos com o processo de mudança capaz de desenvolver a competências dos trabalhadores e obter deles o comprometimento com a busca de soluções para os problemas empresariais emergentes. Portanto, se antes o planejamento de $\mathrm{RH}$ era demandado da própria área; na nova perspectiva o setor assume o status de consultoria interna com estrutura matricial enxuta com as questões do trabalho sendo colocadas de forma a valorizar o capital humano em equilíbrio com a realização do negócio, conforme definido na missão/função social, nas diretrizes, políticas etc. O planejamento da força de trabalho no novo contexto também suscita a realização de inventário e mapeamento de competências para construção dos perfis de competências necessários para as equipes de projetos (times) em que os trabalhadores farão parte nos espaços organizacionais;

- Suprimento: tratava dos processos de recrutamento e seleção que, em sua forma clássica levavam em consideração o conhecimento formal e a experiência das pessoas que ascendiam nas organizações em cargos especializados e em postos fixos de trabalho. No novo contexto, o suprimento é orientado pelo Perfil de Competência Profissional, ou seja, orientado pela construção do perfil de competência para os trabalhadores e os amplos espaços organizacionais que atuarão com foco no mercado e em times de aprendizagem por projetos com liderança compartilhada, estruturas enxutas, processuais, em rede e virtuais para aplicar conhecimentos e atitudes que se referem ao querer fazer e o saber fazer. (Castro e Brito, 2016). Os perfis de competências são composto por conhecimentos, habilidades e atitudes definidas pela organização que são ajustados constantemente a medida da necessidade da organização e seus projetos e traçam uma trilha por onde os trabalhadores devem se desenvolver na busca de sua manutenção nas organizações;

- Aplicação: tinha como função construir as referencias culturais da organização para o trabalhador quanto ao posicionamento dentro de um espaço organizacional e carreira. No novo contexto, os cargos especializados são substituídos por espaços organizacionais interdisciplinares/ multiprofissionais. Flexibilidade favorável à mobilização do trabalhador para as áreas e tarefas em que ele possa agregar mais valor e atender as necessidades da organização, descaracterizando-se a centralização e as estruturas formais das organizações. Nesse novo contexto os trabalhadores poderão atuar em vários times interdisciplinares e multiprofissionais e em vários projetos ao mesmo tempo conforme seu perfil de competências, transitando entre as diversas áreas da organização podendo-se contribuir concomitante e complementarmente com os projetos das áreas de vendas, marketing, compras, finanças, produção, pesquisa etc. atuandose como um consultor de gestão de pessoas para as demais áreas;

- Treinamento e desenvolvimento: antes o processo era focado no indivíduo, cargo, tarefa; agora, o foco está no desenvolvimento das competências profissionais. Os trabalhadores

\footnotetext{
${ }^{1}$ Conjunto de competências centrais (e não periféricas) compostas de: habilidades pessoais, de habilidades de promoção de uma unidade organizacional e de tecnologias de uma empresa, que representam a soma do aprendizado construído ao longo de sua história na realização de negócios no mercado e que faz com que seus produtos sejam percebidos e reconhecidos pelos clientes e concorrentes como vantagem significativa e como produtos agregadores, em termos de qualidade e custos, de benefícios fundamentais e de valores, apresentem diferenciação qualitativa e que não pode ser facilmente copiada entre os concorrentes. (Hamel e Prahalad, 1995).
} 
não ditam mais suas necessidades de capacitação em listas, ou mesmo solicitam suas capacitações conforme sentem que precisam através de check lists, pois a organização através do Perfil de Competências Profissionais traçado é quem direciona a capacitação dos trabalhadores. Uma das estratégias utilizadas pelas organizações para desenvolver os trabalhadores com as competências de que precisam são as universidades corporativas, que se configuram como centros de qualificação profissional com foco no desenvolvimento do trabalhador para o trabalho na organização, fugindo da lógica tradicional das universidades públicas e privadas de preparação do estudante para o mercado de trabalho, conforme o Quadro 3.

Quadro 3: Papel das Universidades Tradicionais e Corporativas

\begin{tabular}{|l|l|}
\hline \multicolumn{1}{|c|}{ Universidades Tradicionais } & \multicolumn{1}{c|}{ Universidades Corporativas } \\
\hline $\begin{array}{l}\text { Desenvolver competências essenciais para o mundo do } \\
\text { trabalho. }\end{array}$ & $\begin{array}{l}\text { Desenvolver competências essenciais para o sucesso do } \\
\text { negócio. }\end{array}$ \\
\hline $\begin{array}{l}\text { Aprendizagem baseada em sólida formação conceitual } \\
\text { e universal. }\end{array}$ & Aprendizagem baseada na prática dos negócios. \\
\hline Sistema Educacional Formal. & $\begin{array}{l}\text { Sistema de Desenvolvimento de Pessoas pautado pela } \\
\text { Gestão de Competências. }\end{array}$ \\
\hline Ensina crenças e valores universais. & $\begin{array}{l}\text { Ensina crenças e valores da empresa e do ambiente de } \\
\text { negócios. }\end{array}$ \\
\hline Desenvolver cultura acadêmica. & Desenvolver cultura empresarial. \\
\hline $\begin{array}{l}\text { Formar cidadãos competentes para gerar o sucesso das das } \\
\text { instituições e da sociedade. }\end{array}$ & $\begin{array}{l}\text { Formar cidadãos competentes para gerar o sucesso da } \\
\text { empresa e dos clientes. }\end{array}$ \\
\hline
\end{tabular}

Fonte: Eboli (1999, p. 117).

Portanto, passa-se de um contexto aonde há a preponderância de aulas expositivas e teóricas, de aprendizagem baseada em conceitos acadêmicos, de ensino de crenças e valores universais em cursos regulados por lei e estruturados segundo normas governamentais, para preponderância de metodologias que privilegiam a aprendizagem por meio de atividades práticas no trabalho, de estudos de casos concretos, simulações, onde o conhecimento está ligado as necessidades estratégicas da organização e cujo ensino é de crenças e valores do ambiente de negócios. (Mundim e Ricardo, 2004).

- Manutenção: enquanto se tinha remuneração fixa focada no cargo; no novo contexto têm-se planos de Remuneração Estratégica, ou seja, remuneração variável focada nos resultados, bem como recompensa para os trabalhadores mais fieis e que agregaram mais valor para as organizações. Nesse contexto, emergem programas internos de premiação por desenvolvimento de novos produtos, serviços, estratégias de gestão que incentivam a inovação e o "empreendedorismo" dos trabalhadores como uma forma de agregar capital e propriedade intelectual para as organizações;

- Controle: tradicionalmente era exercido pelo chefe e se restringia a anotação de dados de cada trabalhador ou mesmo registro nos sistemas informatizados. A grande mudança é que deixa de ser pontual e exercido pelo superior para ser um processo integrado que permeia todo o processo de gestão de pessoas, ou seja, todos controlam todos apoiados por tecnologias avançadas. Nesse cenário, emergem novos cargos como o de gestor do conhecimento que passa a ter como característica a de incentivar a criação do conhecimento, a disseminação, a 
contribuição, a avaliação e filtragem do conhecimento realmente necessário para a organização. O conhecimento é extraído dos trabalhadores nas linhas de trabalho para os repositórios institucionais de modo que todos os demais trabalhadores tenham acesso - propriedade intelectual da organização. Além disso, o gestor assume a função de mentor dos trabalhadores no desenvolvimento de sua trilha de competências.

A Figura 1, demonstra como se dá a articulação do processo de Gestão de Competências, Gestão do Conhecimento e Organizações de Aprendizagem no contexto da ressignificação da gestão de pessoas.

Figura 1: Articulação do processo de Gestão de Competências, Gestão do Conhecimento e Organizações de Aprendizagem.

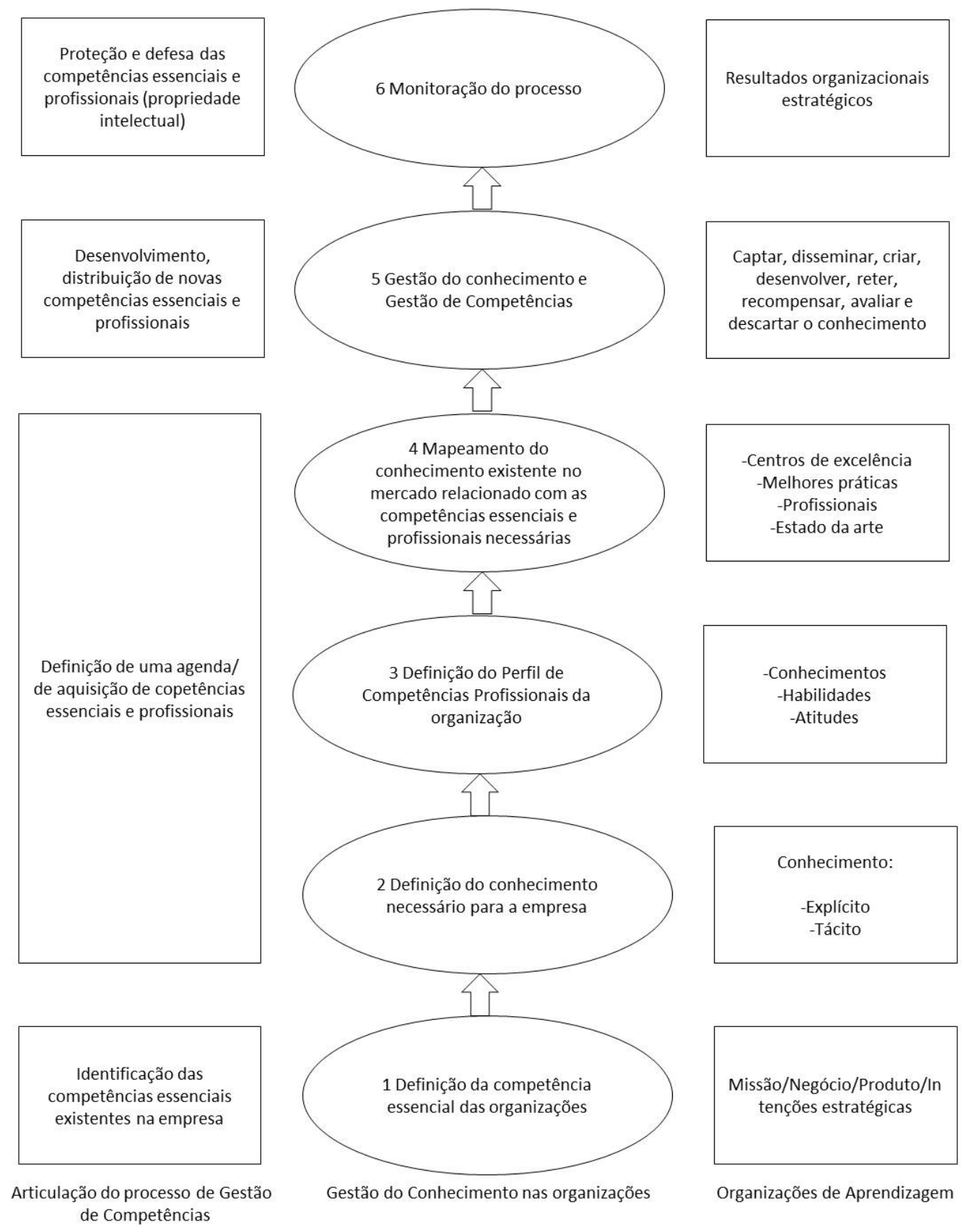


Fonte: Adaptado de Brito (2005, p. 109).

De modo geral, nesse novo contexto, conforme Schlesinger et al. (2008); Margherita e Secundo (2009); Strauhs et al. (2012); Kianto, Ritala, Spender e Vanhala (2014); Freire et al. (2016), a educação para o trabalho se configura como a espinha dorsal da gestão do trabalho com pessoas tornando-se uma questão estratégica para as organizações, pois passa a ser o processo viabilizador para transformação do conhecimento tácito dos trabalhadores em conhecimento explícito, conforme o Quadro 4, além de ser o desenvolvedor das competências requeridas pelas organizações e fomentador da inovação contínua.

Quadro 4: Dimensões do conhecimento, características e formas de aquisição

\section{Conhecimento Explícito}

Características: articulado em linguagem formal, codificada, estruturada, sistematizada, podendo ser afirmações gramaticais, expressões matemáticas, especificações, descrições, manuais, banco de dados, comunicações visuais e sonoras, e deve ser compreensível para qualquer um que entende a simbologia na qual ele é transmitido, podendo ser facilmente comunicado, compartilhado e acessado. Forma de aquisição: educação formal

Formal

Sistematização/Codificação

Fonte: Adaptado de Castro e Brito (2016, p.305).
Conhecimento Tácito

Características: conhecimento pessoal incorporado à experiências de trabalho, às habilidades, expertises, envolve fatores intangíveis como crenças, valores, objetivos pessoais, conclusões, insights, feeling, palpites subjetivos, emoções, ideais, competências, raciocínio, modelos mentais, ideias, opiniões, intuição e criatividade. O conhecimento tático é automático, oral e pode ser difícil comunica-lo. Forma de aquisição: experiência

Autonomia/Criatividade

Além da ressignificação da área de gestão de pessoas, o papel das organizações ainda é o de promover condições facilitadoras para o desenvolvimento dos trabalhadores do conhecimento.

As condições facilitadoras ou o que Choo (2003) chamou de "condições capacitadoras", representam a adoção de práticas voltadas à criação do conhecimento pelas organizações a partir do conhecimento que reside nas pessoas. Meister (1999); Brito (2005); Schlesinger et al. (2008); Strauhs et al. (2012), citam como exemplo as seguintes práticas: educação corporativa, portais corporativos do conhecimento, memória organizacional, mapas de conhecimento, $e$ business, benchmarking, comunidades de práticas, sistemas de informação (intranet, workflow, groupware, inteligência artificial, business intelligence, innovation supporte tools etc.), gestão de pessoas alinhada à criação do conhecimento (gestão por competências), gestão de conversas e ideias, criação de cargos de gestor do conhecimento, gestão de documentos etc.

Essas condições capacitadoras permitem que as organizações tenham ideia de como fomentar a criação e disseminação do conhecimento a fim de manter a vantagem competitiva e até mesmo servir de modelo para diretores e gerentes de organizações, sejam públicas ou privadas, para fomentar a diferenciação através da inovação. Assim as organizações intensificam sua atuação com foco em sua competência essencial, mudam sua forma de funcionamento e de 
remuneração e estimulam o desenvolvimento das habilidades das pessoas, como pode ser observado no Quadro 5.

Quadro 5: A resposta organizacional para um ambiente complexo

\begin{tabular}{|c|c|c|}
\hline $\begin{array}{l}\text { Aumento da Complexidade } \\
\text { Ambiental }\end{array}$ & $\begin{array}{c}\text { Requisitos para lidar com a } \\
\text { Complexidade }\end{array}$ & Resposta Organizacional \\
\hline $\begin{array}{l}\text {-Aumento da turbulência } \\
\text {-Contexto econômico instável } \\
\text {-novas oportunidades de mercado } \\
\text {-ameaça dos concorrentes } \\
\text {-alianças estratégicas pressão da } \\
\text { comunidade }\end{array}$ & $\begin{array}{c}\text {-Agilidade } \\
\text {-Flexibilidade } \\
\text {-Geração de inovações } \\
\text {-Capacidade para } \\
\text { lidar com } \\
\text { informações }\end{array}$ & $\begin{array}{l}\quad \text { Times Autogerenciáveis } \\
\text {-Visão sistêmica } \\
\text {-Aprendizado constante } \\
\text {-multiespecialização } \\
\text {-empowerment } \\
\text {-autonomia } \\
\text {-pró-atividade } \\
\quad \text { Sistema de Sustentação } \\
\text { Sistema de Remuneração por } \\
\text { Competências }\end{array}$ \\
\hline
\end{tabular}

Fonte: Wood Jr. e Picarelli Filho (1995, p. 60).

Também se faz importante destacar o papel dos programas de treinamento e desenvolvimento para as organizações, pois de acordo com Brito et al. (2007) tem como objetivo maior tornar as organizações mais eficazes e consequentemente desenvolver as habilidades organizacionais - as core competências, e individuais.

Portanto, os programas de T\&D além de ajudarem a criar uma cultura de transferência do conhecimento, desenvolver estratégias cognitivas e atitudes que poderão tornar os indivíduos mais competentes para desempenhar vários papéis, também corroboram para melhorar processos, usar novas tecnologias e, sobretudo, criar ambientes que favoreçam a inovação constante. (Von Krogh, Ichijo e Nonaka, 2001; Borges-Andrade et al., 2006; Tasca, Ensslin e Ensslin, 2011).

Esse novo contexto de mudança de paradigma na gestão de pessoas pelas organizações com conotação funcionalista, que conheceremos em seguida, requer um novo posicionamento dos trabalhadores nas organizações.

\subsection{O papel dos trabalhadores do conhecimento}

O papel dos "trabalhadores do conhecimento" num contexto de mudança para a Gestão do Conhecimento é estudado conforme Fukunaga et al (2015) desde 1962, quando Fritz Macchulp publicou o primeiro estudo sobre o assunto. Porém, a consolidação do termo, conforme Pyoria (2005) ocorreu com a evolução dos estudos publicados por Drucker (1995), quando caracterizou os Trabalhadores do Conhecimento como executivos do conhecimento que sabem alocar o conhecimento para uso produtivo da mesma forma que o capitalista sabe alocar o capital para uso produtivo.

O trabalho baseado no conhecimento segundo Fukunaga et al $(2015$, p. 3): 
é caracterizado pelo uso de informações em situações específicas de trabalho, além da criatividade e da autonomia do trabalhador. Os trabalhadores do conhecimento são tomadores de decisão e trabalham com ideias e conceitos. Ou seja, o foco do trabalho depende mais do intelecto do que da força física, caracterizadas por tarefas não repetitivas.

Portanto, o trabalho baseado no conhecimento advém do capital intelectual adquirido através da educação formal ou da experiência (tentativa e erro, por exemplo) exigindo-se mudanças constantes e adaptações às necessidades das organizações.

Trabalhadores do Conhecimento são papéis profissionais organizacionais que viabilizam a Gestão do conhecimento na organização.

Quadro 6 - Papéis na Gestão do Conhecimento

\begin{tabular}{|c|c|c|c|c|c|}
\hline $\begin{array}{c}\text { Nonaka e } \\
\text { Takeuchi } \\
\text { (1997) }\end{array}$ & Stewart (1998) & $\begin{array}{c}\text { Davenport e } \\
\text { Prusak (1998) }\end{array}$ & Meister (1999) & $\begin{array}{l}\text { Goldsmith } \\
\text { (2003) }\end{array}$ & $\begin{array}{c}\text { Bukowitz e } \\
\text { Willams (2002) }\end{array}$ \\
\hline- & - & $\begin{array}{c}\text { Diretores de } \\
\text { Conhecimento }\end{array}$ & $\begin{array}{c}\text { Diretor de } \\
\text { aprendizagem }\end{array}$ & - & $\begin{array}{c}\text { Gestor do } \\
\text { conhecimento }\end{array}$ \\
\hline $\begin{array}{l}\text { Gerentes do } \\
\text { Conhecimento }\end{array}$ & - & $\begin{array}{c}\text { Gerentes de } \\
\text { Projeto do } \\
\text { Conhecimento }\end{array}$ & - & - & $\begin{array}{c}\text { Coordenador } \\
\text { de } \\
\text { conhecimento }\end{array}$ \\
\hline $\begin{array}{l}\text { Engenheiro do } \\
\text { Conhecimento }\end{array}$ & - & - & - & - & - \\
\hline $\begin{array}{l}\text { Especialistas do } \\
\text { Conhecimento }\end{array}$ & $\begin{array}{c}\text { Trabalhadores } \\
\text { do } \\
\text { conhecimento }\end{array}$ & $\begin{array}{l}\text { Trabalhadores } \\
\text { da Gestão do } \\
\text { Conhecimento }\end{array}$ & - & Coach; Mentor & $\begin{array}{c}\text { Ciberotecários; } \\
\text { Expert }\end{array}$ \\
\hline $\begin{array}{l}\text { Operadores do } \\
\text { conhecimento }\end{array}$ & - & $\begin{array}{c}\text { Pessoal } \\
\text { orientado para } \\
\text { o } \\
\text { Conhecimento }\end{array}$ & - & Trainee; Mentee & - \\
\hline
\end{tabular}

Fonte: Oliveira, Castro e Brito (2016, p. 7).

Como se pode observar no quadro acima, existe o consenso entre alguns autores de que devem existir pelo menos três níveis de papéis para a concretização da GC. Num primeiro nível estão os diretores e gerentes do conhecimento que são os altos gerentes e os gerentes seniores de uma organização cuja

[...] função básica [...], é a gerencia do processo total de conhecimento organizacional no nível da empresa. [...] Os gerentes do conhecimento dão senso de direção às atividades de criação do conhecimento de uma empresa, (1) expressando os conceitos principais sobre o que a empresa deve ser; (2) estabelecendo uma visão do conhecimento sob a forma de uma visão da empresa ou declaração de políticas; e (3) estabelecendo padrões que justifiquem o valor do conhecimento que está sendo criado (Nonaka e Takeuchi, 1997, p. 288).

No segundo nível estão gerentes de nível médio que são os engenheiros do conhecimento que através da criação de conceitos de nível intermediário de negócio e produto, conseguem o equilíbrio entre "o que é" e "o que deve ser". Eles são capazes de refazer a realidade projetandose o conhecimento segundo a visão da organização. Eles sintetizam o conhecimento tácito tanto 
dos funcionários da linha de frente quanto dos executivos seniores, tornando-o explícito e incorporam esse conhecimento a novas tecnologias, produtos ou sistemas.

No nível intermediário também estão os especialistas, ou seja, o profissional experimentado e que tem profundo conhecimento em determinada área e que é responsável por construir e julgar uma porção específica de informação e transformá-la em conhecimento. Eles podem ser utilizados como filtros humanos de informação (Bukowitz e Williams, 2002, p. 82). Neste nível estriam também os Ciberotecários - intermediários de informação eletrônica e da Internet, que junto com os gestores de conhecimento e especialistas em conteúdo, podem orientar os empregados para os sites da Internet que contêm informação útil.

Finalmente têm-se os operadores do conhecimento, aqueles que acumulam e geram conhecimento tácito rico na forma de habilidades incorporadas baseadas na experiência.

Os papéis de GC são muito importantes, pois significa ajudar os trabalhadores a compartilhar o que eles sabem que sabem, pois uma pessoa pode saber muito sobre determinada área, mas a menos que escreva sobre isso, crie uma apresentação, monitore ou exponha, o conhecimento beneficia somente uma pessoa, pois a raiz da aprendizagem organizacional é a noção de que as organizações, através de seus membros, devem ser capazes de adquirir novos conhecimentos e agir sobre eles, renovando, assim, o contexto do qual a aprendizagem futura brotará. (Skerlavaj, Song e Lee, 2010; Scoot, 2010; Rakhsh e Ahmadi, 2011; Shehzad e Khan, 2013; Wahyuningsih e Astuti, 2013).

Segundo Reinhardt et al. (2011), a criação de um tipologia de papéis do trabalhador de conhecimento provoca a distinção entre funções relacionadas com a obtenção, utilização, disseminaçao e gestão do conhecimento com as funções clássicas de RH. No novo contexto, os trabalhadores do conhecimento devem: monitorar o desempenho da organização a partir de várias informações, transferir informações e ajudar os demais trabalhadores a resolver os problemas do dia a dia, utilizar a informação e as atividades práticas para a melhoria das suas habilidades e competências pessoais, associar e combinar informações de diferentes áreas e recursos para gerar novas, construir relações pessoais e profissionais com pessoas envolvidas no mesmo tipo de trabalho compartilhando e oferecendo informações e suporte, planejar suas atividades e as da organização, pesquisar e coletar informações sobre determinado fenômeno, disseminar informações, identificar caminhos para a resolução dos problemas organizacionais e reagir antecipando problemas futuros tanto individuais quanto organizacionais.

No Quadro 7 Fukunaga et al (2015) faz uma relação entre o que chamou de 13 processos típicos de conhecimento, que são classificados por Brito (2005) e Marques (2015) como processos da gestão de pessoas ressignificados, com o papel dos Trabalhadores do Conhecimento. 


\begin{tabular}{|c|c|}
\hline \multicolumn{2}{|r|}{ Análise dos Processos versus Papéis } \\
\hline $\begin{array}{l}13 \text { Processos típicos de } \\
\text { Conhecimento }\end{array}$ & Papel do Trabalhador do Conhecimento (baseado na Atividade) \\
\hline Aquisição & $\begin{array}{l}\text { Com altos picos de importância os papéis de Recuperador, Aprendiz, } \\
\text { Solucionar, Linker, Rastreador atuam nesse processo. }\end{array}$ \\
\hline $\begin{array}{l}\text { Análise e Busca } \\
\text { Informação }\end{array}$ & $\begin{array}{l}\text { Todos os respondentes indicaram que atuam nestes processos com } \\
\text { mais relevância os papéis de solucionador, recuperador e aprendiz. } \\
\text { Esses papéis coletam com muitas quantidades de informações para } \\
\text { resolver problemas, encontrar dados para ajudar as pessoas. }\end{array}$ \\
\hline $\begin{array}{l}\text { Autoria, Coautoria e } \\
\text { Busca de Serviços }\end{array}$ & $\begin{array}{l}\text { Pouca aderência nas atividades no papel do trabalhador, destacada } \\
\text { pelo autor como resultado da autoria e coautoria inesperada por } \\
\text { conta da Teoria de Criação do Conhecimento de Nonaka e Takeuchi } \\
(1995)\end{array}$ \\
\hline Disseminação & $\begin{array}{l}\text { Fortes picos nos papéis do compartilhador, networker e auxiliar, e } \\
\text { média no papel de um organizador que para Reinhardt et al. (2011) foi } \\
\text { maior do que o esperado. }\end{array}$ \\
\hline Busca especializada & $\begin{array}{l}\text { Networker e o Solucionador utilizam periodicamente desse processo } \\
\text { em suas atividades }\end{array}$ \\
\hline Feedback & $\begin{array}{l}\text { Aprendiz, Disseminador e o Controlador obtiveram médio destaque } \\
\text { neste processo. }\end{array}$ \\
\hline $\begin{array}{l}\text { Organização da } \\
\text { Informação }\end{array}$ & $\begin{array}{l}\text { Forte pico no papel do aprendiz, seguido do organizador e } \\
\text { recuperador. }\end{array}$ \\
\hline Aprendizagem & $\begin{array}{l}\text { Como esperado pelo autor o Aprendiz teve alto pico neste processo, } \\
\text { além do Solucionador e Recuperador. }\end{array}$ \\
\hline $\begin{array}{l}\text { Monitoramento e } \\
\text { Relacionamento }\end{array}$ & $\begin{array}{l}\text { Além do Networker e Recuperador os papéis de Compartilhador e } \\
\text { Aprendiz também necessitam de relacionar-se com especialistas para } \\
\text { serem produtivos. }\end{array}$ \\
\hline
\end{tabular}

Fonte: Fukunaga et al (2015, p.7).

Entretanto, a forma como cada um desempenha o seu papel, vai depender do modelo gerencial e consequentemente do processo decisório de criação do conhecimento utilizado nas organizações, conforme o Quadro 8.

Quadro 8: Modelos Gerenciais de Criação do Conhecimento

\begin{tabular}{|c|c|c|c|c|}
\hline \multicolumn{2}{|r|}{ Modelos Gerenciais } & Top-down & Bottom-up & Middle-up-down \\
\hline \multirow{3}{*}{ Quem } & $\begin{array}{c}\text { Agente de criação do } \\
\text { Conhecimento }\end{array}$ & Alta gerência & Indivíduo empreendedor & $\begin{array}{c}\text { Equipe / gerencia de } \\
\text { nível médio }\end{array}$ \\
\hline & Papel da alta gerencia & Comandante & Patrocinadora / Mentora & Catalisadora \\
\hline & $\begin{array}{l}\text { Papel da gerencia de nível } \\
\text { médio }\end{array}$ & $\begin{array}{l}\text { Processadora de } \\
\text { informações }\end{array}$ & $\begin{array}{l}\text { Intra-empreendedora } \\
\text { autônoma }\end{array}$ & Líder da equipe \\
\hline \multirow[b]{2}{*}{ Qual } & Conhecimento acumulado & Explícito & Tácito & Explícito e tácito \\
\hline & $\begin{array}{l}\text { Conversão do } \\
\text { conhecimento }\end{array}$ & $\begin{array}{l}\text { Conversão parcial } \\
\text { focalizada na } \\
\text { combinação / } \\
\text { internalização }\end{array}$ & $\begin{array}{c}\text { Conversão parcial } \\
\text { focalizada na socialização / } \\
\text { externalização }\end{array}$ & $\begin{array}{c}\text { Conversão em espiral } \\
\text { de internalização/ } \\
\text { externalização/ } \\
\text { combinação / } \\
\text { socialização }\end{array}$ \\
\hline Onde & $\begin{array}{l}\text { Armazenamento do } \\
\text { Conhecimento }\end{array}$ & $\begin{array}{c}\text { Banco de dados } \\
\text { computadorizado / } \\
\text { manuais }\end{array}$ & Personificado no indivíduo & $\begin{array}{c}\text { Base de } \\
\text { conhecimento } \\
\text { organizacional } \\
\end{array}$ \\
\hline \multirow{3}{*}{ Como } & Organização & Hierarquia & $\begin{array}{c}\text { Equipe de projeto e rede } \\
\text { informal }\end{array}$ & $\begin{array}{l}\text { Hierarquia e força- } \\
\text { tarefa (hipertexto) }\end{array}$ \\
\hline & Comunicação & Ordens/instruções & $\begin{array}{l}\text { Princípio de auto- } \\
\text { organização }\end{array}$ & $\begin{array}{c}\text { Diálogo e uso de } \\
\text { metáfora/ analogia }\end{array}$ \\
\hline & Tolerância à ambigüidade & $\begin{array}{c}\text { Não permite caos / } \\
\text { flutuação }\end{array}$ & $\begin{array}{c}\text { Caos / flutuação como } \\
\text { premissa }\end{array}$ & $\begin{array}{c}\text { Cria e amplifica caos / } \\
\text { flutuação }\end{array}$ \\
\hline
\end{tabular}




\begin{tabular}{|c|c|c|c|}
\hline Ponto fraco & $\begin{array}{c}\text { Alta dependência } \\
\text { da alta gerência }\end{array}$ & $\begin{array}{c}\text { Consome muito tempo; } \\
\text { custos de coordenação dos } \\
\text { indivíduos }\end{array}$ & $\begin{array}{c}\text { Exaustão humana; } \\
\text { custo da redundância }\end{array}$ \\
\hline $\begin{array}{c}\text { Exemplo de organização onde foi } \\
\text { implantado }\end{array}$ & $\begin{array}{c}\text { General Electric } \\
(\mathrm{GE}) /\end{array}$ & (3 M) & Canon \\
\hline
\end{tabular}

Fonte: Adaptado de Nonaka e Takeuchi (1997).

No modelo Top-dow, os conceitos são criados pela cúpula da organização, e o processo decisório é de cima para baixo, no modelo Middle-up-down os conceitos são construídos e a decisão acontece no nível intermediário pelas equipes de trabalho e no modelo Bottom-up os conceitos são criados de baixo para cima pelos indivíduos inventores e empreendedores.

Segundo Shepherd e Sutcliffe (2011), o maior desafio desse campo ainda é desenvolver uma teoria organizacional útil voltada para Gestão do Conhecimento, que perpassa a mudança da cultura organizacional de burocrática para flexível (por processos, virtuais e em rede) (SENGE, 2012), considerando-se que uma nova teoria tem maior possibilidade de contribuir se for uma teoria mais ampla; mais simples; mais explícita sobre as interconexões; e com menos explicações alternativas e barreiras à sua aplicação.

Portanto, os papéis profissionais, como os modelos gerenciais, por exemplo, servem para contextualizar que a GC carece de reconhecimento no interior das organizações para prover benefícios para seus clientes/beneficiários.

\section{CONSIDERAÇÕES PROVISÓRIAS}

A partir do objetivo da pesquisa, tem-se que o destaque no papel dos trabalhadores diante dos modelos emergentes de gestão, entre eles: a Gestão por Competências, Gestão do Conhecimento e Organizações de Aprendizagem, é saber alocar o conhecimento para uso produtivo, combinar competências no processo criativo para gerar a inovação, desenvolver a escolaridade viabilizando-se o saber fazer através das experiências e da proficiência práticas para construção de novos conhecimentos, desenvolver atitude cooperativa para saber trabalhar em equipes complementares e multidisciplinares, procurar o desenvolvimento e atualização constante das competências requeridas pela organização através de educação e treinamento para o trabalho.

Quanto as organizações, tem como papel, apoiar e estimular as atividades criadoras de conhecimento dos indivíduos, ou seja prover condições facilitadoras para o desenvolvimento dos trabalhadores, sendo: mapas mentais, autonomia, provocar a mudança para acender a criatividade dos trabalhadores, educação para o trabalho, portais corporativos, memória organizacional para registrar as contribuições dos trabalhadores, fomentar programas de treinamento para o desenvolvimento dos perfis de competências dos trabalhadores e para construção das core competências organizacionais, criar uma cultura de transferência do conhecimento, desenvolver estratégias cognitivas e atitudes que poderão tornar os indivíduos mais competentes para desempenhar vários e novos papéis, viabilizar novas tecnologias, flexibilizar suas estruturas departamentais por equipes, criar ambientes que favoreçam a inovação e, sobretudo, ressignificar a gestão de pessoas com foco nas estratégias organizacionais como o meio de alavancar a inovação e o empreendedorismo constantemente. 
Nesse contexto, de consolidação de papeis das organizações e das pessoas, se rompe o círculo vicioso dos modelos clássicos de gestão para a criação de uma nova ordem. Espera-se que esta discussão inicial contribua para o aperfeiçoamento e a criação de um novo contraditório sobre o papel das organizações, inclusive como mentoras da ressignificação da gestão de pessoas; contribua ainda sobre a reflexão dos os novos papeis dos trabalhadores, e que fomente elementos ainda não identificados que poderão nortear futuros trabalhos com temas ligados aos novos modelos de gestão em rede, em organizações virtuais e sobre a utilização e a influência das redes sociais para a gestão de pessoas nas organizações.

Para, além disso, a partir dessa reflexão inicial, ainda milita a necessidade de como reverter essa abordagem que tem como objetivo enquadrar o trabalhador sob os interesses da empresa, para uma nova epistemologia que busque fortalecer a posição do trabalhador nas organizações. Uma outra limitação do estudo reside no atual momento em que uma nova ruptura ocorre na relação entre as pessoas e as organizações por meio da institucionalização da terceirização, que passa a atingir, inclusive, o nível estratégico, pois se trata de uma relação triangular entre empregado, empresa contratante e empresa prestadora de serviço com o objetivo de prevalência da lógica do capital.

\section{REFERÊNCIAS}

Bagnoli, C., \& Vedovato, M. (2012). The impact of knowledge management and strategy. J Manag Gov. 18, 615-647.

Becerra-Fernandez, I., Sabherwal, R. (2015). Knowledge Manegement: systems and processes. Routledge: New York.

Besseyre Des Horts, C. (1988). Gérer les ressources humaines dans l'entreprise. Concepts et Outils. Paris: Les Editions D'Organisation.

Borges-Andrade, J. E. et al. (2006). Treinamento, Desenvolvimento e Educação em Organizações e Trabalho: fundamentos para a gestão de pessoas. Porto Alegre: Artmed.

Bukowitz, W. R., \& Williams, R. L. (2002). Manual de gestão do conhecimento: ferramentas e técnicas que criam valor para a empresa. São Paulo: Bookman.

Brinkley, I. (2006). Defining the knowledge economy: knowledge economy programme report. London: The Work Foundation. Part of Lancaster University.

Brito, L. M. P. (2005). Gestão de competências, gestão do conhecimento e organizações de aprendizagem: instrumentos de apropriação pelo capital do saber do trabalhador. Fortaleza: Imprensa Universitária.

Castro, A. B. C. de, \& Brito, L. M. P. (2016). Como o IFRN/Campus são Paulo do Potengi aprende? In: Castro, A. B. C. de, Lima, J. G. S. A. de, Aquino, M. E. S. P. de, \& Silva, U. R. de L. (Org.). Práticas educativas em movimento: experiências formativas de ensino, pesquisa, extensão e gestão no Campus São Paulo do Potengi do IFRN. Natal: IFRN Editora.

Castro, A. B. C. de, \& Brito, L. M. P. (2016). Gestão do Conhecimento: como as organizações públicas do Brasil percebem esse modelo? Revista Gestão Industrial. 12(2), 59-72.

Choo, C. W. (2003). A Organização do conhecimento: como as organizações usam a informação para criar significado, construir conhecimento e tomar decisões. São Paulo: Senac.

Davenport, T., \& Prusak, L. (1998). Conhecimento empresarial: como as organizações gerenciam o seu capital intelectual. Rio de Janeiro: Elsevier.

Drucker, P. F. (1995). Administrando em tempos de grandes mudanças. São Paulo: Pioneira Thomson Learning. 
Eboli, M. et al. (1999). Universidades Corporativas. São Paulo: Schmukler.

França, A. C. L. (2007). Práticas de Recursos Humanos: conceitos, ferramentas e procedimentos. São Paulo: Atlas.

Fukunaga, F., Macedo, V., Santos, N. M. B. F. dos, Carvalho, F. C. A. de., \& Almeida, E. P. (2015). Indicadores bibliometricos da produção acadêmica mundial sobre o conceito do trabalhador do conhecimento. Perspectivas em Gestão \& Conhecimento, João Pessoa, 5, Número Especial, 42-56.

Freire, P. S., Dandolini, G., A.; Souza, J. A. de, Trierweiller, A. C., Silva, S. M. da; Sell, D., Pacheco, R. C. dos S., Todesco, J. L., \& Steil, A. V. (2016). Corporate University Network: Initial Considerations for a New Modelo of Corporate Education. Revista ESPACIOS. 37(5), 2016.

Geisler, E., \& Wickramasinghe, N. (2009). Principles of Knowledge Management: theory, practice, and cases. Routledge: New York.

Goldsmith, M. (2003). Coaching: o exercício da liderança. Rio de Janeiro: Campus.

Hamel, G., \& Prahalad, C. K. (1995). Competindo pelo Futuro: estratégias inovadoras para obter o controle do seu setor e criar mercados de amanhã. São Paulo: Campus.

Kianto, A., Ritala, P., Spender, J., \& Vanhala, M. (2014). The interaction of intellectual capital assets and knowledge management practices in organizational value creation. Journal of Intellectual Capital. 15(3), 362-375.

Kim, T. H., Lee, J., Chun, J. U., \& Benbasat, I. (2014). Understanding the effect of knowledge management strategies on knowledge management performance: A contingency perspective. Information \& Management. 51(4), 398-416.

Leone, N. M. de C. P. G. (2007). Evidências empíricas em face das referências teóricas nas funções estratégicas da gestão de pessoas. In: Brito, L. M. P. (Org.). Práticas de pesquisa em gestão de pessoas 2: a tênue separação entre o público e o privado no Brasil. Fortaleza: Edições UFC.

Massingham, P. (2014). An evaluation of knowledge management tools: Part 1 - managing knowledge resources. Journal of Knowledge Management. 18(6), 1075-1100.

Margherita, A., \& Secundo, G. (2009). The Emergence of th Stakeholder University, em Romano, Aldo. Open Business Innovation Leadership The Emergence of the Stakeholder University. Londres: Palgrave Macmillan, 30(2), 170-206.

Marques, F. (2015). Gestão de Pessoas: fundamentos e tendências. Brasília: DDG/ENAP.

Meister, J. (1999). Educação corporativa: a gestão do capital intelectual através das universidades corporativas. São Paulo: Makron Books.

Mundim, A. P. F., \& Ricardo, E. J. (2004). Educação Corporativa. Rio de Janeiro: Qualitymark.

Nonaka, I., \& Takeuchi, H. (1997). Criação de conhecimento na empresa: como as empresas japonesas geram a dinâmica da inovação. Rio de Janeiro: Campus.

Oliveira, J. A. de, Castro, A. B. C. de, \& Brito, L. M. P. (2016). Gestão do Conhecimento: um estudo em um hospital federal universitário do Nordeste do Brasil. Revista Gestão \& Conhecimento, 10(2), Jul./Dez.

Pyoria, P. (2005). The concept of knowledge work revisited. Journal of Knowledge Management. 4(9), 116-127, Mar.

Rakhsh, P., \& Ahmadi, E. (2011). Creativity, organizational learning, and operation. 2nd International Conference on Education and Management Technology, IPEDR, 13, IACSIT Press, Singapore.

Reinhardt, W., Schmidt, B., Sloep, P., \& Drachsler, H. (2011). Knowledge Worker Roles and Actions - Results of Two Empirical Studies. Knowledge and Process Management. 18(3), 150174.

Senge, P. R. (2012). A quinta Disciplina: arte e prática da organização que Aprende. São Paulo: 
Best Seller.

Scoot, B. B. (2011). Organizational Learning: A Literature Review. Discussion Paper \#2011-02. Queens University, jan.

Schlesinger, C. C. B., Reis, D. R. dos, Silva, H. F. N., Carvalho, H. G. de, Sus, J. A. L. de, Ferrari, J. V., Skrobot L. C., \& Xavier, S. A. de (2008). Gestão do conhecimento na administração pública. [S.I.]: Instituto Municipal de Administração Pública - IMAP.

Shepherd, D. A., \& Sutcliffe, K. M. (2011). Inductive Top-down Theorizing: a Source of New Theories of Organization. Academy of Managament Review. 36(2), 361-380.

Stewart, T. A. (1998). Capital intelectual: a nova vantagem competitiva das empresas. Rio de Janeiro: Campus.

Strauhs, F. do R., Pietrovski, E. F., Santos, G. D., Carvalho, H. G. de, Pimenta, R. B., \& Penteado, R. S. (2012). Gestão do conhecimento nas organizações. Curitiba: Aymará Educação.

Skerlavaj, M., Song, J. H., \& Le, Y. (2010). Organizational learning culture, innovative culture and innovations in South Korean firms. Journal Expert Systems with Applications. 37, 6390-6403.

Ulrich, D. (1998). Os campeões de Recursos Humanos. Inovando para obter os melhores resultados. São Paulo: Futura.

Von Krogh, G., Ichijo, K., \& Nonaka, I. (2001). Facilitando a criação do conhecimento: reinventando a Empresa com o Poder da Inovação Continua. Rio de Janeiro: Campus.

Wahyuningsih, A., Astuti, E. S., Musadieq, M. A. (2013). The Effect of Organizational Learning on Knowledge Management, Capability and Performance of Organization. Journal of Basic and Applied Scientific Research. 3(5), 159-169.

Wood Jr., T., Picarelli Filho, V. (1995). Remuneração estratégica. São Paulo: Atlas. 